\title{
Healthcare Service in Hong Kong and its Challenges
}

The Role of Health Professionals within a Social Model of Health

\section{Veronika Schoeb}

\section{(2) OpenEdition}

\section{Journals}

Electronic version

URL: https://journals.openedition.org/chinaperspectives/7118

DOI: $10.4000 /$ chinaperspectives. 7118

ISSN: 1996-4617

\section{Publisher}

Centre d'étude français sur la Chine contemporaine

\section{Printed version}

Date of publication: 1 December 2016

Number of pages: $51-58$

ISSN: 2070-3449

\section{Electronic reference}

Veronika Schoeb, "Healthcare Service in Hong Kong and its Challenges", China Perspectives [Online], 2016/4 | 2016, Online since 01 December 2017, connection on 07 December 2022. URL: http:// journals.openedition.org/chinaperspectives/7118; DOI: https://doi.org/10.4000/chinaperspectives 7118

All rights reserved 


\title{
Healthcare Service in Hong Kong
}

\section{and its Challenges}

\author{
The Role of Health Professionals within a Social Model of Health
}

\author{
VERONIKA SCHOEB
}

\begin{abstract}
The Hong Kong Special Administrative Region combines a British colonial history within a Chinese cultural context and offers its population a dual system with a comprehensive and efficient public health care system in tandem with private hospitals and practitioners. Multiple challenges are looming: increasing demand for health services due to an aging population, staff shortages at all levels, and an underdeveloped primary healthcare system. Health is determined by multiple factors and is defined as a state of complete physical, mental, and social well-being. In recent years, the medical model of health focusing on pathology and disease has been considered insufficient, and a social model of health has been proposed, relying on a more holistic and broad definition of health. Rather than focusing on individual responsibility for health, the social model emphasises collective responsibility for health. This paper analyses the challenges facing Hong Kong in view of the social model of health. The discussion provides some reflections on medical dominance, the reasons behind limited primary care services, and what steps could be recommended to deliver healthcare services in Hong Kong in line with a more holistic view of health.
\end{abstract}

KEYWORDS: social determinants of health, healthcare delivery, access, healthcare system, Hong Kong, health professionals.

A $\mathrm{n}$ individual's health status is determined by multiple factors. Not only do a person's genetic make-up and lifestyle affect his or her health, but factors such as housing, community networks, and the environment also play an important role in a person remaining healthy. (1) Therefore, where one is born, grows up, lives, and works determines how healthy he or she is. Differences between rural and urban environments, wealth and poverty, as well as education and job opportunities influence the wellbeing and health of an entire population. Hong Kong provides an interesting example for a closer analysis of health service delivery, as the city combines a British colonial history (with a National Health Servicetype universal public health care system) with an adherence to Chinese culture. In comparison with Western countries, Hong Kong's usage of hospital-based care is similar to the US and UK. (2) Although there is a cultural affinity to Traditional Chinese Medicine (TCM), people in Hong Kong favour Western medicine over TCM, particularly for acute health problems. Additionally, while doctors of Western medicine in Hong Kong use TCM for their personal health, they do not necessarily refer patients for TCM treatments. ${ }^{(3)}$ In the context of Western medicine prevailing in Hong Kong, this article will explore some dimensions of Hong Kong's health service delivery in the public health care system and describe the role of health professionals in terms of access.

The Hospital Authority (HA) oversees all of Hong Kong's public hospitals and manages 27,645 hospital beds and nearly 8 million patient days per year. ${ }^{(4)}$ The main challenges of Hong Kong's health system are rising demand due to an increasingly aging population, chronic staff shortages (physicians, nurses, and allied health professionals), and growing waiting lists for access to healthcare. ${ }^{(5)}$ Facing a growing service demand, HA's strategic objectives set out to maintain a skilled and competent workforce, increase service capacity, improve access to health services, and enhance service quality and patient safety. ${ }^{(6)}$ In some Western countries, allied health professions such as physiotherapy and occupational therapy have been promoted and their professional roles expanded to address the shortage of primary care practitioners. Yet, medical dominance continues to determine Hong Kong's health policy, reinforcing the classical view of professional hierarchy.

Medical dominance also favours a medical model of health, characterised by a biomedical understanding of health focusing on disease or disability and that encourages personal individual responsibility. An alternative model is the social model of health, which offers a broad understanding of health and emphasises collective social responsibility. ${ }^{(7)}$ In today's healthcare system, the medical model still prevails, but evidence points to the need for including social dimensions into healthcare service delivery as a means of addressing the populations' health needs.

1. Michael Marmot and Richard G. Wilkinson (eds), Social Determinants of Health, 2nd edition, Oxford, Oxford University Press, 2006.

2. Gabriel M. Leung, Irene OL Wong, Wai-Sum Chan, Sarah Choi, and Su-Vui Lo, "The Ecology of Health Care in Hong Kong," Social Science \& Medicine, Vol. 61, No. 3, 2005, pp. 577-590.

3. Vincent CH Chung, Sheila Hillier, Chung Hong Lau, Samuel YS Wong, Eng Kiong Yeoh, and Sian M. Griffiths, "Referral to and Attitude towards Traditional Chinese Medicine amongst Western Medical Doctors in Postcolonial Hong Kong," Social Science \& Medicine, Vol. 72, No. 2, 2011, pp. 247255.

4. Hospital Authority, "Annual Plan 2015-16," www.ha.org.hk/haho/ho/ap/AP1516E-1.pdf (accessed on 17 December 2015).

5. Mark Britnell, In Search of the Perfect Health System, London, Palgrave, 2015

6. Ibid.

7. Louise Warwick-Booth, Ruth Cross, and Diane Lowcock, Contemporary Health Studies: An Introduction, Cambridge, UK, Polity Press, 2012. 
This article will explore the challenges that Hong Kong faces in keeping its population healthy in terms of healthcare access as one of the determinants of health, and considers the role physicians and allied health professionals can play in enhancing the health of Hong Kong's population. The structure of this article is (1) to present an overview of Hong Kong's healthcare system and shortcomings with a focus on access, (2) to explore key aspects that determine the health of a population, (3) to analyse the roles of health professionals regarding access within the social model of health, and (4) to discuss how to address Hong Kong's challenges with regard to its health service delivery.

\section{Hong Kong's healthcare system}

Hong Kong's healthcare system has some similarity to the British NHS when it comes to public hospital care. The Food and Health Bureau is responsible for policies and resource allocation for all of Hong Kong Health Services. ${ }^{(8)}$ Ninety percent of bed days are provided by the public hospital system, with the remaining share covered by private hospitals. ${ }^{(9)}$ The private system, on the other hand, takes on about $70 \%$ of all fee-for-service outpatient services compared to public outpatient clinics. ${ }^{(10)}$ The public system is guided by the Hospital Authority ( $\mathrm{HA})$ and is organised into seven clusters serving the entire population of Hong Kong with subsidised medical care. This type of organisation should ensure that patients receive high-quality healthcare services within the same geographical area and throughout the course of an illness (from acute care to rehabilitation and community care) and their lifetime.

The clusters are divided into geographical areas:

- Kowloon East Cluster

- Kowloon Central Cluster

- Kowloon West Cluster

- New Territories East Cluster (includes Prince of Wales Hospital associated with the Faculty of Medicine, Chinese University of Hong Kong)

- New Territories West Cluster

- Hong Kong West Cluster (includes Queen Mary Hospital associated with the Faculty of Medicine, University of Hong Kong)

- Hong Kong East Cluster

The private hospital system, loosely associated within the Hong Kong Private Hospitals Association, includes 12 private hospitals. ${ }^{(11)}$ While this dual track system is organised separately, there are several government initiatives, such as the eHR (electronic health record) programme and the Voluntary Personal Insurance Scheme that intend to foster collaboration between the two systems. ${ }^{12}$ ) Figure 1 provides an overview of the organisation of Hong Kong's healthcare systems: ${ }^{(13)}$

\section{Current challenges for Hong Kong's healthcare system and government responses}

The challenges Hong Kong faces with regard to its healthcare system are multiple. On the one hand, an overstretched public hospital system leads to long waiting times for non-emergency procedures (e.g. cataract surgery, joint replacement surgery), as well as to heavy workloads for clinical staff. (14) While the standard of care in public and private hospitals is generally high, the public system can hardly cope with the demand for a number of surgical procedures in certain Clusters. For example, Hong Kong West Cluster pa- tients have a waiting time of 70 weeks for joint replacement surgery, whereas a patient in Kowloon Central can have a joint replaced within 14 weeks. ${ }^{(15)}$

Aware of uneven distribution within the healthcare system, the Government of Hong Kong SAR has tried to shift some of the burden from the public system to private practitioners by proposing a public-private partnership, so-called PPP, to more rapidly respond to the needs of the population. ${ }^{(16)}$ The proposals include all levels of care from primary care to secondary and tertiary care. Programs in primary care include the Vaccination Subsidy Scheme (VSS), in which eligible Hong Kong residents (e.g., pregnant women, elders, children under 12 years) are entitled to a HK\$190 subsidy for influenza vaccinations provided by private doctors. ${ }^{(17)}$ Since 2009, the Elderly Health Care Voucher Scheme (HCVS) provides a HK\$2,000 subsidy to elderly over 70 years of age who hold a valid Hong Kong ID card. They can then use the vouchers for services provided by private practitioners (e.g. nurses, physiotherapists, dentists, radiographers). ${ }^{(18)}$ However, a study investigating the willingness of Hong Kong's elderly to pay for primary care services revealed that less affluent service users in particular were worried about affordability and uncertain about the quality of providers in the private sector. ${ }^{(19)}$ The study suggested that "financial incentives for consumers alone may not be enough to promote primary care or public-private partnership" (p. 117). (20) In secondary care, partnerships were established, e.g., the Shared Care Program aimed at allowing patients with chronic disease (diabetes, hypertension) to receive care from private practitioners instead of getting treatment within the public hospital system. In a recent evaluation of all PPPs in Hong Kong, E. Wong et al. (21) showed that PPPs were able to "extend the private sector's complementary role to the public sector" (p. 267), at least in some of the programs. However, the study also identified complicated processes and lack of financial incentives inhibiting the success of some of the schemes. In addition, lack of coordination among government agencies, and a lack of expertise and information made the PPPs challenging. Under these circumstances, it is not surprising that citizens have

8. Food and Health Bureau, www.fhb.gov.hk; Covernment of HK website, "Overview of the Health Care System in Hong Kong," www.gov.hk/en/residents/health/hosp/overview.htm (both URLs accessed on 16 November 2016).

9. Mary C. Schooling, Lai Ling Hui, Lai Ming Ho, Tai-Hing Lam, and Gabriel M. Leung, "Cohort Profile: 'Children of 1997': A Hong Kong Chinese Birth Cohort," International Journal of Epidemiology, Vol. 41, No. 3, 2011, pp. 611-620

10. Ibid.

11. The Hong Kong Private Hospitals Association, www.privatehospitals.org.hk (accessed on 17 March 2016).

12. Idem.

13. Government Hong Kong, "Overview of the Healthcare System in Hong Kong," op. cit.

14. Hospital Authority, "Annual Plan 2015-16," op. cit.

15. Hospital Authority, "Waiting Time for Total Joint Replacement Surgery," www.ha.org.hk/visitor/ ha_visitor_text_index.asp?Content_ID=221223\&Lang=ENG\&Dimension=100\&Parent_ID=21417 2\&Ver=TEXT (accessed on 06 November 2015).

16. Hospital Authority, "Public Private Partnership," http://www3.ha.org.hk/ppp (accessed on 6 November 2015)

17. Centre for Health Protection, "Vaccination Subsidy Scheme," www.chp.gov.hk/en/view_content/ 45849.html (accessed on 25 October 2016).

18. The Government of HKSAR, "Health Care Voucher," www.hcv.gov.hk/eng/pub_service_area.htm (accessed on 25 October 2016).

19. Su Liu, Carrie HK Yam, Olivia HY Huang, and Sian M. Griffiths, "Willingness to Pay for Private Primary Care Services in Hong Kong: Are Elderly Ready to Move from the Public Sector?", Health Policy and Planning, Vol. 28, No. 7, 2013, pp. 717-729.

20. Ibid.

21. Eliza LY Wong, Eng-kiong Yeoh, Patsy YK Chau, Carrie HK Yam, Annie WL Cheung, and Hong Fung, "How Shall We Examine and Learn about Public-private Partnerships (PPPS) in the Health Sector? Realist Evaluation of PPPs in Hong Kong," Social Science \& Medicine, No. 147, 2015, pp. 261-269. 


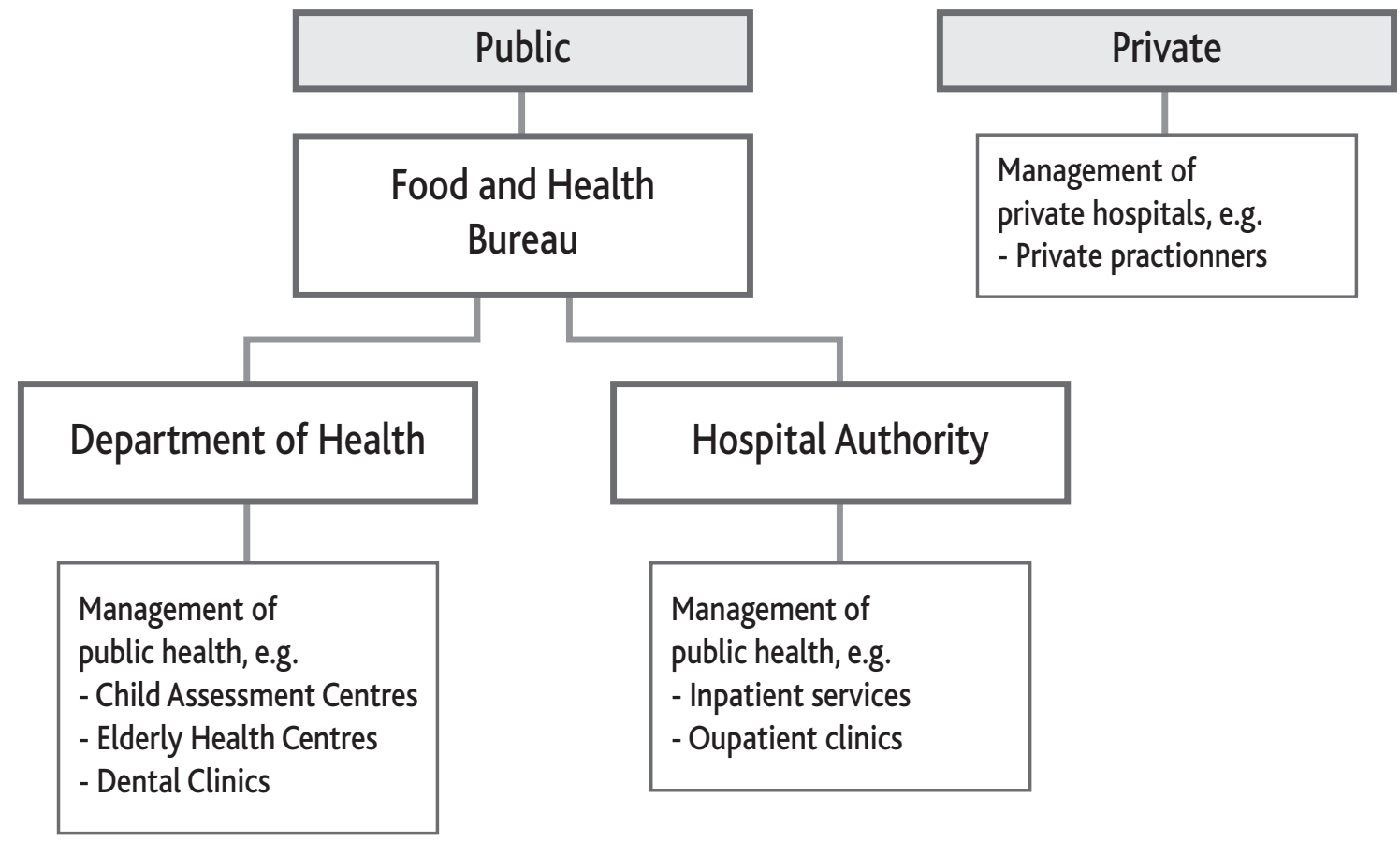

been slow to enrol in these public-private partnership programs, and that health professionals have been critical of these government initiatives. (22)

Although PPPs have not proven to be a panacea for healthcare reform, the government needs to find solutions to remediate higher demand due to an increasing elderly population and the increasing prevalence of chronic diseases and to address the overstretched public health system. The Chief Executive in his last policy address set out the following plan: ${ }^{(23)}$

- To further promote primary care to ensure a sustainable public healthcare system;

- To allocate HK\$10 billion to the Hospital Authority to set up an endowment fund to generate investment returns in order to regularise the clinical public-private partnership programmes (PPP);

- To provide around 2,400 additional hospital beds: an acute general hospital will be completed in the Kai Tak Development Area (Tin Shui Wai Hospital, Children's Hospital).

Increasing service demand and staff shortages are leading to an inadequate health service delivery with long waiting times for certain procedures. The Hong Kong SAR government has attempted several healthcare finance reforms, with the latest one targeting a move into private-public partnerships. Many of the previous suggested initiatives did not pass the scrutiny of the public and health professionals so that the status quo was maintained. How does this governing style affect frontline practitioners? The next section provides an overview of the health service delivery dimension and its challenges, the environment in which health professionals interact with individuals and communities.

\section{Delivery of health services and its challenges}

Staff shortages, workforce issues, health insurance coverage, and timeliness of services are important factors, among others, influencing the access shortcomings that Hong Kong faces. ${ }^{(24)}$

\section{Staff shortages}

As mentioned before, one of Hong Kong's prevailing problems is the shortage of health professionals. Medical services are already sometimes understaffed but will be short of medical professionals in the near future. It is projected that public hospitals will require an additional 6,200 medical doctors by 2041 in order to maintain the same level of services as today. ${ }^{(25)}$ In order to remedy this outlook, the Hong Kong government has allowed the two medical schools in the city to increase the number of medical school graduates from 250 last year to 420 by 2018 . ${ }^{(26)}$ Additional measures are to increase the retirement age for medical doctors from 60 to 65 years ${ }^{(27)}$ and to allow overseas doctors to take jobs at public hospitals on a special temporary licence, renewed annually by the Medical Council. (28) However, access to practice for foreign trained medical doctors is limited, as they have to apply for registration by passing a three-part exam (professional knowledge, English, and clinical examination) and participate in a 12month internship before they can become registered. ${ }^{(29)} \mathrm{A}$ reform to address the composition of the Medical Council in order to improve its efficiency

22. Sabrina Ching Yuen Luk, Health insurance reform in Asia, New York, Routledge, 2014

23. The Government of HKSAR, "2016 Policy Address" (paragraphs 220 to 223), www.policy address.gov.hk/2016/eng/p220.html (accessed on 19 January 2016).

24. Office of Disease Prevention and Health Promotion, "Access to Health Services," HealthyPeople.gov, www.healthypeople.gov/2020/topics-objectives/topic/Access-to-Health-Services (accessed on 16 November 2016).

25. "Hong Kong's Doctor Shortage Will Not Ease until 2020: Government Report," South China Morning Post, 3 March 2015, www.scmp.com/news/hong-kong/article/1728880/plan-increase-medical-school-places-beat-chronic-doctor-shortage (accessed on 19 January 2016).

26. Ibid:; The Government of HKSAR, "2016 Policy Address" (paragraphs 220 to 223), op. cit.

27. The Government of the HKSAR, Food and Health Bureau, "Report of the Steering Committee on Review of Hospital Authority," www.legco.gov.hk/yr14-15/english/panels/hs/papers/hs201507 20cb2-1907-1-e.pdf (accessed on 19 January 2016).

28. "Foreign Doctors Quit Hong Kong Public Hospitals over License Red Tape," South China Morning Post, 20 October 2014, www.scmp.com/news/hong-kong/article/1620172/foreign-doctors-quithong-kong-public-hospitals-over-licence-red-tape?page=all (accessed on 19 January 2016).

29. Medical Council of Hong Kong, "Licensing Examination," www.mchk.org.hk/licensing_exam/ index_e.htm (accessed on 26 March 2016). 
in handling complaints and thereby to enhance transparency was blocked by medical professionals and the Legislative Council (LegCo). ${ }^{(30)}$ This failed attempt to reform the Medical Council demonstrates the tension between rationally solving the staff shortage crisis by giving access to potential entrants and keeping the exclusive status of the medical profession. By maintaining a majority in the Medical Council, the medical profession is able to self-regulate and keep its authority over the workforce. ${ }^{(31)}$

Apart from medical staff shortages and approaches to remedy these, Hong Kong's healthcare system relies heavily on allied health professionals to address the population's function and mobility. A shortage of allied health professionals leaves many vacancies in both public hospitals (Hospital Authority) and NGOs (Services provided under the Department of Health). The lack of physiotherapists and occupational therapists providing services to Hong Kong's elders is shocking: 34 percent of 174 elderly services units cannot fill open vacancies. ${ }^{(32)}$ While the government is aware of this issue, as a discussion in the Legislative Council session on 11 March 2015 shows, ${ }^{(33)}$ politicians need to strike a balance "between the need to train more healthcare professionals for meeting future demand and the capacity constraint of universities which cannot have their teaching infrastructure expanded overnight." (34) However, while the limited capacity of universities to accommodate increased student intake might certainly be a challenge, it seems questionable whether the medical profession is interested in change, as it is not interested in losing control over healthcare service delivery.

\section{Health insurance coverage}

All patients in Hong Kong have access to public healthcare services when they are in need, but increasingly with delay. The transfer from public to private practitioners in order to decrease the backlog applies to both medical and allied health services. ${ }^{(35)}$ While there is a six-month waiting period for some outpatient clinics in the public system, private outpatient clinics can usually take patients without delay. However, the private clinics have their own market value and often charge their clients higher rates. Private insurance companies tend to negotiate their rates with individual clinics, or patients can pay out of pocket. Yet, self-pay is only possible for people with sufficient means and makes healthcare services less accessible to people with limited financial resources. The delivery of health services is therefore influenced by the patient's insurance coverage or financial means. When access to the public system is limited due to increased demand, health insurance coverage becomes a determinant factor for healthcare access. While quality service is the hallmark of a good healthcare system, negative financial incentives (co-payments) will influence choices of healthcare providers. ${ }^{(36)}$

\section{Services/Workforce}

Striving for high-quality patient care is a priority for all health professionals. Each professional is held accountable for providing evidence-based care at a reasonable cost. ${ }^{(37)}$ In order to enhance primary care in an environment of medical staff shortages, nursing and allied health professionals can step in to cover part of the services. Having these professions as primary care providers - which is the case in several countries, such as the US, Australia, UK, and Norway - not only gives the profession a higher social status but also provides better care for patients. ${ }^{(38)}$ Historically, scholars in Hong Kong have not been in favour of recommending direct access to the services of allied health professionals. ${ }^{(39)}$ Nevertheless, the Hong Kong government has formed a task force to evaluate the role of physiotherapists in primary care and to see whether the referral system could be modified in order to provide better services to the population. Whether this proposed initiative could help improve access to services given the general staff shortage remains to be seen.

\section{Timeliness of services}

Timeliness for healthcare services is closely linked to staff shortages. When, for example, a patient with knee pain consults a primary care physician, and a referral for physiotherapy services is issued, the patient's treatment in an overcrowded public system would be delayed unless the patient decides to go to a private clinic (at higher cost or with a partial subsidy through health care vouchers). Actual and perceived delays in getting care reflect significant barriers to care, jeopardising the quality of healthcare services. ${ }^{(40)}$ In Hong Kong, the elderly population is particularly vulnerable, facing significant difficulties in accessing primary healthcare services. ${ }^{(41)}$ For example, elderly living in Hong Kong's lower socio-economic status neighbourhoods are more likely to be hospitalised for avoidable healthcare problems, ${ }^{(42)}$ thereby not only increasing the cost of healthcare services but also creating a heavier burden due to the shortage of staff.

Given the need for improving Hong Kong's health services, the biggest challenge the city will face in the near future is to keep delivering high quality healthcare in a timely fashion and to maintain and enhance the population's health (e.g., health promotion and prevention). To achieve this, and as reviewed in this section, factors related to access need to be addressed. These factors have typically been discussed within a traditional medical model, but considering the social determinants of health is crucial if the health of an entire population is to be enhanced. The next section will shed light on this discussion by introducing the social model of health.

30. "Hong Kong's Doctor Shortage Will Not Ease until 2020: Government Report," art. cit.

31. Arthur Sweetman, James Ted McDonald, and Lesleyanne Hawthorne, "Occupation Regulation and Foreign Qualification Recognition: An Overview," Canadian Public Policy, Vol. 41, Supplement 1, 2015, pp. S1-13.

32. "Staff Shortages in Hong Kong Threaten Quality of Care for Elderly," South China Morning Post, 15 July 2015, www.scmp.com/news/hong-kong/health-environment/article/1839255/staffshortages-hong-kong-threaten-quality-care (accessed on 4 September 2015).

33. Legislative Council Panel of Health Services, "Manpower Projections for Doctors, Dentists and Nurses," for discussion on 11 March 2015, LC Paper No. CB(2)978/14-15(03), www.legco.gov.hk/yr14-15/english/panels/hs/hs_hps/papers/hs_hps20150311cb2-978-3-e.pdf (accessed on 4 September 2015).

34. Ibid.

35. The Government of HKSAR, Food and Health Bureau, "Regulation of Private Healthcare Facilities: Consultation Document," www.gov.hk/en/theme/bf/consultation/pdf/Regulation_of_PHFs_ con_doc_e.pdf (accessed on 18 September 2015).

36. Lieke HHM Boonen, Bas Donkers, and Frederik T. Schut, "Channeling Consumers to Preferred Providers and the Impact of Status Quo Bias: Does Type of Provider Matter?", Health Services Research, Vol. 46, No. 2, 2011, pp. 510-530

37. World Confederation for Physical Therapy, "WCPT guideline for standards of Physical Therapy Practice," 2011, www.wcpt.org/sites/wcpt.org/files/files/Guideline_standards_practice_complete.pdf (accessed on 18 September 2015).

38. World Confederation for Physical Therapy, "Direct Access and Self-referral to Physical Therapy: Findings from a Global Survey of WCPT Member Organisations," 2013, www.wcpt.org/sites/ wcpt.org/files/files/Direct_access_SR_report_Jan2013.pdf (accessed on 18 September 2015).

39. Angel Oi-Ping Chan, A Study on the Direct Access to Physiotherapy in Hong Kong, Master thesis, University of Hong Kong, China, 2008.

40. US Department of Health \& Human Services, Agency for Healthcare Research and Quality, "National Healthcare Disparities Report 2008,"Washington, 2008, Chapter 3, "Access to healthcare," (AHRQ publication; No. 09-0002), https://archive.ahrq.gov/research/findings/nhqrdr/nhdr08/ Chap3.html (accessed on 24 November 2016).

41. Pui Hing Chau, Jean Woo, Michael K. Gusmano, Daniel Weisz, Victor G. Rodwin, and Kam Che Chan, "Access to Primary Care in Hong Kong, Greater London and New York City," Health Economics, Policy and Law, Vol. 8, No. 1, 2013, pp. 95-109.

42. Ibid. 


\section{Social model of health: The social determinants of health}

Some appalling news is brought to us in Sir Michael Marmot's latest book, The Health Gap: The Challenge of an Unequal World: (43) for example, (1) the US spends much more on healthcare than any other country, but maternal death rates there are as high as in Greece, or (2) life expectancy is 20 years less in one low-income neighbourhood in Clasgow, Scotland, compared to its affluent counterpart only 30 minutes away. ${ }^{(44)}$ Multiple factors play a role in a population's health status, but health professionals are particularly well placed to "initiate and develop services that take into account, and attempt to improve, the wider social context for patients and staff." (45)

Several models exist that explain the complex interaction between multiple determinants of health. ${ }^{(46)}$ The model proposed here is the "Rainbow Model" developed by Dahlgren and Whitehead (47) (see also a review of the DETERMINE consortium), ${ }^{(48)}$ which was also included in the WHO report on the social determinants of health. ${ }^{(49)}$ This model underlines the importance of policies, governance, and the political context, as these factors influence health and health (in)equities within a healthcare system.

\section{The Rainbow Model of social determinants of health}

The Rainbow Model is a layered model, starting from the individual at the centre, moving on to community networks, the individuals' living and working conditions, and then encompassing general socio-economic, cultural, and environmental conditions.

Individual characteristics having an influence on health, such as age, sex, gender, hereditary and genetic factors as well as personality are usually taken into consideration when healthcare professionals address the health needs of patients and communities. However, most clinical interventions focus on individual lifestyle factors, such as diet, exercise, weight control, etc. Traditionally, health professionals aim to "convince" or "persuade" people of the benefits of a healthy lifestyle, and to incite them to "adhere" to remedies such as exercise, healthy diet, and work-life balance. Big global campaigns such as "Exercise is Medicine" promote this approach and hold individuals (and their lifestyle choices) responsible for their health. ${ }^{(50)}$ In Hong Kong, the Physical Fitness Association in collaboration with associations in the field of sport, rehabilitation, physiotherapy, and medicine joined forces to develop courses on "exercise prescription" and to collaborate with the Hong Kong Ministry of Health on training healthcare professionals to emphasise an active and healthy lifestyle. (51)

In recent years, behavioural approaches to health improvement have been suggested as a way to improve the health of the population. Frequently cited models are the transtheoretical model of change ${ }^{(52)}$ or Bandura's Social Cognitive Theory of self-efficacy. ${ }^{(53)}$ They both emphasise individual responsibility for health. These theories are rooted in the discipline of social psychology and incorporate a cognitive behaviourist paradigm. ${ }^{(54)}$ Yet, these models only minimally consider a person's social support and social capital, which are crucial for health. Social support implies that a person feels loved and trusted and receives empathy and that the social support system is beneficial with regard to appraisal (receiving feedback), information, or even receiving money or time from people close-by. ${ }^{(55)}$ Social capital entails participation in community groups, ${ }^{(56)}$ including relationships with neighbours (known as "bridging social capital"), or family ("bonding social capital"). (57) Overall, social environmental factors and their impact on lifestyle factors are still understudied - in contrast to individual factors that have been investigated extensively - but are slowly emerging as key determinants for understanding health behaviour. ${ }^{(58)}$

The living and working conditions of a population - the next layer in the model - are of utmost importance for health. ${ }^{(59)}$ It is easy to imagine that a non-skilled worker earning less than a white collar worker might be at risk of suffering from a high level of stress, and of being exposed to an unhealthy environment. Food is vital, and malnutrition, over- and under-consumption, is of epidemic dimension. ${ }^{(60)}$ While improving the aforementioned factors might have a tremendous impact on population health, healthcare practitioners have only minimal control over education, work environment, or housing. These dimensions are influenced by policies and general socio-economic, cultural, and environmental conditions, the last layer in the model. Policy is now widely recognised as a determinant of health: social policy (e.g., education) affects children and adults, and social welfare policies tend to support poor individuals and the elderly. It has been demonstrated that countries that invest more money in housing, food assistance programs, employment programs, and social services have children born with higher birth weight, lower infant mortality, and longer

43. Michael Marmot, The Health Gap: The Challenge of an Unequal World, London, Bloomsbury, 2015. 44. Ibid.

45. Matilda Allen, Jessica Allen, Sue Hogarth, and Michael Marmot, Working for Health Equity: The Role of Health Professionals, London, UCL Institute of Health Equity, 2013.

46. Trevor Hancock and Fran Perkins, "The Mandala of Health: A Conceptual Model and Teaching Tool," Health Education, Vol. 24, No. 1, 1985, pp. 8-10; Diana Daghofer and Peggy Edwards, Toward Health Equity: A Comparative Analysis and Framework for Action, Final Report, 2009, http://opha.on.ca/getmedia/c4536b04-2ce1-44e8-8b40-81bfe75be8f9/HealthEquityComparativeAnalysis-FinalReport-Mar2009.pdf.aspx?ext=.pdf (accessed on 17 December 2015).

47. Göran Dahlgren and Margaret Whitehead, Policies and Strategies to Promote Equity in Health, Copenhagen, Denmark, World Health Organization, Regional Office for Europe, 1992.

48. Ingrid Stegeman, Caroline Costongs, and Clive Needle (on behalf of the DETERMINE Consortium), The Story of DETERMINE: Mobilising Action for Health Equity in the EU, 2010, http://eurohealthnet.eu/sites/eurohealthnet.eu/files/publications/DETERMINE-Final-Publication-Story.pdf (accessed on 17 December 2015)

49. World Health Organization, Closing the Gap in a Generation: Health Equity through Action on the Social Determinants of Health: Final Report of the Commission on Social Determinants of Health, Geneva, 2008.

50. Exercise is Medicine Hong Kong, Fact Sheets Hong Kong, www.exerciseismedicine.org/assets/documents/pdf_files/2015\%20International\%20Prospectus_EIM\%20Hong\%20Kong.pdf (accessed on 8 September 2015)

51. Ibid.

52. James O. Prochaska and Carlo C. DiClemente, The Transtheoretical Approach:Crossing Traditional Boundaries of Therapy, Homewood, IL, Dow Jones-Irwin, 1984.

53. Albert Bandura, "Self-efficacy: Toward a Unifying Theory of Behavioural Change," Psychological review, Vol. 84, No. 2, 1977, pp. 191-215.

54. Richard J. Siegert and William J.Taylor, "Theoretical Aspects of Goal-setting and Motivation in Rehabilitation," Disability and Rehabilitation, Vol. 26, No.1, 2004, pp. 1-8.

55. World Health Organization, Closing the Gap in a Generation: Health Equity through Action on the Social Determinants of Health: Final Report of the Commission on Social Determinants of Health, op. cit.

56. Emma Kirkby-Geddes, Nigel King, and Alison Bravington, "Social Capital and Community Group Participation: Examining 'Bridging' and 'Bonding' in the Context of a Healthy Living Centre in the UK," Journal of Community \& Applied Social Psychology, Vol. 23, No. 4, 2013, p. 271-285.

57. World Health Organization, Closing the Gap in a Generation: Health Equity through Action on the Social Determinants of Health: Final Report of the Commission on Social Determinants of Health, op. cit.

58. Lorna Haughton McNeill, Matthew W. Kreuter, and S.V. Subramanian, "Social Environment and Physical Activity: A Review of Concepts and Evidence," Social Science \& Medicine, Vol. 63, No. 4, 2006, pp. 1011-1022.

59. World Health Organization, Closing the Gap in a Generation: Health Equity through Action on the Social Determinants of Health: Final Report of the Commission on Social Determinants of Health, op. cit.

60. Jean Kinsey, "Will Food Safety Jeopardize Food Security?", Agricultural Economics, Vol. 32, No. s1, 2005, pp. 149-158. 
life expectancies. (61) Furthermore, there is substantial evidence that education is linked to health and to (risky) health behaviour or preventative service use. ${ }^{(62)}$

Having reviewed Hong Kong's healthcare system and its challenges (Section 1) and put it in the perspective of what determines health (Section 2), we can now appreciate in the next section the role that Hong Kong's health professionals play in delivering optimal health services to their population. A discussion follows in the last section.

\section{The role of health professionals in Hong Kong's healthcare system}

Medical, nursing, and allied health professionals are at the heart of Hong Kong's health service delivery. Even though non-medical experts (e.g., social workers, government agencies) also participate in delivering healthcare-related services, the focus of this paper is on regulated health professions. Medical doctors are often the entry point for patients, as they deal with acute and chronic health problems by taking into consideration physical, psychological, social, cultural, and existential dimensions. While these aspirations are commendable, they often function within a medical rather than social model of health. ${ }^{(63)}$ Since the beginning of the twentieth century, the narrow focus on individuals rather than on the wider perspective of a patient's social situation and the environment has led to many gains in understanding diseases and has helped to develop important scientific breakthroughs (e.g., penicillin), but more person-centred and community-based care is required today. ${ }^{(64)}$

As an example of allied health professions, physiotherapy emerged from a different historical background, having gained importance as a profession in the early twentieth century to re-educate polio victims and rehabilitate soldiers wounded in war. ${ }^{(65)}$ In general, physiotherapists are experts at helping patients and clients maintain or improve functional mobility and thereby enhance the quality of life of various populations. They require skills in identifying movement disorders and offer treatment interventions to address these limitations.

The nursing profession has undergone a major transformation worldwide as well as in Hong Kong. Having started as an apprenticeship model where nursing students were trained on hospital wards, nursing education is nowadays a university-based education with clinical placements. Several specialty areas are registered by the Nursing Council: General Nursing, Mental Health Nursing, and Paediatric Nursing. ${ }^{(66)}$ The role of nurses is dynamic and everchanging, taking account of societal changes and technological advances. They contribute to "preventing ill-health; attending to emergency and acute disease exacerbation; managing long term health conditions; and offering end-of-life care" across all age groups. ${ }^{(67)}$

All professionals require knowledge, attitude, and multiple skills to perform at a high professional standard and to provide quality care to individuals and the population. However, it is important to highlight the fact that the health professions are regulated professions, meaning that the profession can only be executed by professionals who hold a registration in Hong Kong According to Elkin, ${ }^{(68)}$ Registration Boards have the duty to ensure public protection and to promote safe practice while at the same time they need to enable adequate coverage of services for the population. A specific registration board for each profession regulates the health professions in the Hong Kong SAR: the Medical Council oversees the registration of physicians and is guided by the Medical Registration Ordinance (Chapter 161); ${ }^{(69)}$ the
Nursing Council is responsible for registration of nurses (Chapter 164); ${ }^{70)}$ and the Physiotherapist Board regulates professionals under the "Supplementary Medical Professions Ordinance" (Chapter 359). (71) By looking closer at the composition of the council/board, however, we note that while the chairman of the Medical Council is a physician, and the chairwoman of the Nursing Council a nurse, in the case of the Physiotherapy Board the chairman is a medical doctor. This suggests that the medical profession in Hong Kong is not only a referral source for allied health professions (and gatekeeper) but also holds power over the registration boards of other professions. Freidson (72) argues that physicians, a self-regulated profession, exert social control through the power of knowledge and through the hierarchical skills structure (delegation of tasks to a lowerskilled professional). Occupying the chairmanship of an allied health profession's regulatory body clearly establishes the medical authority in Hong Kong's health system.

\section{Hong Kong's challenges in improving health service delivery}

The previous sections have identified Hong Kong's shortcomings of access to and delivery of health services. Some challenges are related to the structure of the healthcare system and the division of labour amongst health professions, whereas others are more connected to government policies. The medical profession has been and continues to be the main authority for providing healthcare services in Hong Kong and delegating tasks to allied health professionals and nurses. Nevertheless, to promote healthy communities and improve the health of the population, all nursing and allied health professions have an essential part to play and need to contribute to serving

61. Michael Marmot and Richard Wilkinson, Social Determinants of Health: The Solid Facts, op. cit, James Krieger and Donna L. Higgins, "Housing and Health:Time Again for Public Health Action," American Journal of Public Health, Vol. 92, No. 5, 2002, pp. 758-768; Ernie Hood, "Dwelling Disparities: How Poor Housing Leads to Poor Health," Environmental Health Perspective, Vol. 113, No. 5, 2005, pp. A310-317.

62. Leon Feinstein, Ricardo Sabates, Tashweka M. Anderson, Annik Sorhaindo, and Cathie Hammond, "What Are the Effects of Education on Health?", OECD Proceedings of the Copenhagen Symposium: Measuring the Effects of Education on Health and Civic Engagement, 2006, www.oecd.org/edu/innovation-education/measuringtheeffectsofeducationonhealthandcivicengagement.htm (accessed on 8 September 2015).

63. Mike Bury, Health and Illness, Cambridge, Polity Press, 2005

64. Justin Allen, Bernard Gay, Harry Crebolder, Jan Heyrman, Igor Svab, and Paul Ram, "The European Definitions of the Key Features of the Discipline of General Practice: The Role of the GP and Core Competencies," British Journal of General Practice, Vol. 52, No. 479, 2002, pp. 526-527.

65. Olga Dreeben-Irimia, Introduction to Physical Therapy, Sudbury, MA, Jones and Bartlett Publisher, 2010.

66. Nursing Council Hong Kong (HKNC), "Core-competencies and Reference Guide," www.nchk.org.hk/en/core_competencies_and_reference_guides/index.html (accessed on 25 October 2016)

67. HKNC, "Scope of Professional Practice," www.nchk.org.hk/filemanager/en/pdf/scope_english.pdf (accessed on 25 October 2016).

68. Katie Elkin, "Registration Decision-making, and Public Protection: International Medical Graduates in Australia and New Zealand," Canadian Public Policy, Vol. 41, No. 1 Supplement, 2015, pp. S162172.

69. HKSAR, Department of Justice, "CAP 161 Medical Registration Ordinance," www.legislation.gov.hk/ blis_pdf.nsf/6799165D2FEE3FA94825755E00033E532/1BEAC46DCBF4AFFC482575EE0047F3A5 (accessed on 26 October 2016).

70. HKSAR, Department of Justice, "CAP 164 Nurses Registration Ordinance," www.legislation.gov.hk/ blis_pdf.nsf/6799165D2FEE3FA94825755E0033E532/DD338BA272231278482575EE004884E4? OpenDocument\&bt=0 (accessed on 26 October 2016)

71. HKSAR, Department of Justice, "CAP 359 Supplementary Medical Professions Ordinance," www.legislation.gov.hk/blis_ind.nsf/WebView?OpenAgent\&vwpg=CurAllEngDoc*359*0*359\#35 9 (accessed on 26 October 2016)

72. Eliot Freidson, Professional Powers: A Study of the Institutionalization of Formal Knowledge, Chicago, University of Chicago Press, 1986 
the communities. The future development of primary care services in Hong Kong will be significant. Working within a social model of health encourages less hierarchical relations between professionals and might define the roles of health professionals differently. Each patient-provider contact could be an opportunity for health professionals to address the social determinants of health and to improve the quality of clinical services. However, the current prevalence of a medical model and medical dominance limit the development of community services in Hong Kong. Being an advocate for patients and communities will not be sufficient to address Hong Kong's challenges. Healthcare financing (beyond PPP) as well as a restructuring of service delivery might have to be considered in future. Healthcare finance reform has been on the radar in Hong Kong for many years but has never received sufficient support from the population, health professionals, and legislators. Last, but not least, educating the next generation of health professions with regard to a social model of health is one of the options to consider. Let's review these points in more detail:

\section{Development of primary care services}

Health professionals are very well placed to address the social determinants and thereby improve population health. Initiatives can easily be started in any workplace without having to make big changes. In the US, for example, paediatricians propose to address the social determinants of health explicitly by:

- screening for social determinants during medical visits (psychosocial issues, depression, violence);

- collocating community-based resources to improve access (information);

- developing outside-the-box multidisciplinary primary care interventions. ${ }^{(73)}$

In the UK, health professionals are encouraged to approach patients as follows: ${ }^{(74)}$

1) Relationships: Practitioners build trust and respect with their patients and maintain a strong collaboration with local communities;

2) Gathering information: Taking a social history in addition to medical information enables practitioners to provide the best care for their patients or refer them further if necessary;

3) Providing information: Information about various services, such as agencies, organisations, or social services, helps tackle the root causes of ill health.

With the Rainbow Model of social determinants of health becoming more widespread, practitioners have a framework to systematically address the different factors contributing to the health of individuals and communities.

However, one of the biggest challenges for this paradigm shift to primary care is the monopolisation of medicine by physicians. Physicians represent a powerful occupational group at the top of the hierarchy who not only have the mandate to self-regulate their own profession but also to regulate other allied health professions. In addition to the structural hierarchy, Hong Kong society is based on Chinese values of collectivism, indicating that the group becomes more important with a "sense of duty toward the group" and "conformity with group norms" rather than emphasising individual achievements and pursuit of one's own perspectives. ${ }^{(75)}$ Medical profession- als in Hong Kong have a high social status, and medical judgments are usually respected and perceived by the public as true and valid. ${ }^{(76)}$ The other health professions are then socialised into this system and accept this unchallengeable authority. ${ }^{(77)}$

Moreover, as regulated professions they provide insiders with a degree of monopoly and exert authority over entrance requirements. ${ }^{(78)}$ By reducing access to newcomers, this dominance can result in increasing prices and reducing services to clients, ${ }^{(79)}$ which is not for the benefit of society. Regulation of health professions restricts the supply of labour and is a factor contributing to staff shortages in Hong Kong. The government must strike a balance between availability (sufficient quantity), accessibility, and quality, ${ }^{\left({ }^{80}\right)}$ ensuring public safety but allowing competent healthcare practitioners to work. In comparison, Australia's striving for availability and accessibility of services took precedence over stringent registration requirements, potentially to the detriment of quality medical service provision. ${ }^{(81)}$ While public protection is important, regulation must at the same time satisfy the wider interest of society when trying to target public health objectives. (82) Up until now, Hong Kong, a bureaucratic post-colonial administrative region, has not succeeded in convincing the medical profession of the importance of a Medical Council reform. The powerful medical profession holds monopoly power and thereby protects its own group. Freidson in his seminal study on professional powers argues that by establishing selfregulation for new entrants and also assigning superior and inferior credentials, medical professionals ensure their top position in the hierarchy, giving them "social control." As authority in Chinese culture goes unchallenged, the dominance of the medical profession persists, thereby hindering the development of primary care services that rely on a much more collaborative approach and flat hierarchy.

\section{Healthcare financing initiatives and structure of healthcare delivery}

The Government of Hong Kong SAR has proposed multiple initiatives over the years to alleviate the burden on the public system and to transfer healthcare delivery to private practitioners. While public-private partnerships are a current trend worldwide, the programs in Hong Kong have not been sufficiently endorsed by the population and by health professionals. The population is quite satisfied with the quality of care in the public system and believes that healthcare services should be provided free (provided by

73. Arvin Garg, Brian Jack, and Barry Zuckerman, "Addressing the Social Determinants of Health within the Patient-Centered Medical Home Lessons from Pediatrics," JAMA, Vol. 309, No. 19, 2013, pp. 2001-2002.

74. Matilda Allen, Jessica Allen, Sue Hogarth, and Michael Marmot, Working for Health Equity: The Role of Health Professionals, op. cit.

75. Eva GT Green, Jean-Claude Deschamps, and Dario Paez, "Variation of Individualism and Collectivism within and between 20 Countries: A Typological Analysis," Journal of Cross-cultural Psychology, Vol. 36, No. 3, 2005, pp. 321-339.

76. Cheng Yuk-Ling, Structural Empowerment among Frontline Nurses in Hong Kong: A Study of Cultural and Personality Factors (Thesis), University of Hong Kong, Pokfulam, Hong Kong SAR, 2012.

77. Ibid.

78. Arthur Sweetman, James Ted McDonald, and Lesleyanne Hawthorne, "Occupation Regulation and Foreign Qualification Recognition:An Overview," Canadian Public Policy, Vol. 41, No. Supplement 1, pp. S1-13.

79. Ibid.

80. UNESCO, Towards a UNESCO culture and development indicators suite - Dimension No. 5: Cultural dimension in human rights and development, working document, 2000, Access: www.unesco.org/fileadmin/MULTIMEDIA/HQ/CLT/creativity/pdf/culture_and_development_indicators/Di mension\%205\%20Human\%20rights.pdf (accessed on 27 October 2016).

81. Katie Elkin, "Registration Decision-making, and Public Protection: International Medical Graduates in Australia and New Zealand," Canadian Public Policy, op. cit.

82. Ibid. 
the $\mathrm{HA}$ ). A recent study (83) revealed that patients in Hong Kong have difficulty booking a primary care visit when they get sick, indicating that access to services is not sufficient. Furthermore, results indicated that the quality of primary care services in Hong Kong was associated with income, increasing the inequality for lower socioeconomic groups of the population. ${ }^{(84)}$ If health services are to be provided to the entire population equally, the government needs to not only educate the public through a wide-spread campaign but also create incentives for practitioners to promote specific programs. As shown with recent initiatives, without the support of the medical profession and incentives that go with it, healthcare financing reforms will be shelved and ideas buried in the bureaucracy of the administration. A user-oriented, collaborative initiative rather than a top-down administrative instruction might facilitate the necessary shift from a hospital-based secondary and tertiary healthcare system to primary care services.

\section{Education of future health professionals}

Changes in healthcare systems can also be tackled through the education of new health professionals. To achieve a less hierarchically structured and collaborative healthcare delivery system in Hong Kong, increasing focus should be placed on the social determinants of health. ${ }^{(85)}$ The contemporary curricula for Health Sciences (medicine, nursing, allied health professions) are focused on the instruction of clinical expertise, especially to diagnose individuals' biological or psychological problems (medical model of health). While knowledge about social aspects of health is essential, skills such as communication or advocacy skills are necessary to tackle health inequalities. Taking a social history, for example, should be embedded in any health professional curriculum, but is currently often neglected in the formal education of health professionals. In addition, students should learn to reflect on their own model of health: do they adhere to a medical model or a social model of health? Research evidence indicates that medical practitioners and allied health professionals often foster a biomedical and clinician-centred approach (86) by working in a medical model rather than pertaining to a social model of health. Education is an excellent way to guide students and future professionals in reflecting on health service delivery, the social determinants of health, and the impact they can have on the health of individuals and communities.

\section{Conclusion}

This paper has explored the social model of health that takes into account wider influences on health, and emphasises collective and social responsibility for health. Factors such as employment, education, community networks, and environment have an important impact on the health status of individuals as well as on communities. Patients' problems should not be seen as merely health troubles originating in the individual, but also need to be assessed with regard to community networks and policy aspects. This paper sheds light on Hong Kong's healthcare context and analyses the challenges it faces in relation to demand - an overstretched public hospital system due to an ever-growing aging population - and the limited offer of services due to staff shortages. The article expands further on the role of health professionals and explores how they might address the various dimensions of the social determinants of health.

The role of health professionals within a paradigm of the social model of health could be the key for improved healthcare services in general, as well as access to healthcare for the population. Even in a public health system as efficient as Hong Kong's, access might increasingly be at risk due to staff shortages, issues related to health insurance coverage, and increasing waiting lists for certain procedures (timeliness). Whether the public-private partnership can address these challenges remains to be seen. The social model of health redefines how health is conceptualised and reconsiders the role of health professionals in providing appropriate and high-quality healthcare services. A few suggestions to achieve this balance are proposed, from a more one-on-one approach of improved communication in order to understand clients' lives and address certain aspects within the community networks, to a more policy-oriented approach of healthcare financing and regulation of health professionals. The questions are complex: What kind of healthcare do we want for Hong Kong's population? Are health professionals able to provide better healthcare for a wider population by practicing within a social model of health? This article argues that models such as the Rainbow Model of social determinants of health might be a useful tool for reflecting upon the practices of health professionals in Hong Kong and elsewhere in the world and to address some of the shortcomings of the current system.

\section{Veronika Schoeb is assistant professor, Department of Rehabilitation Sciences, The Hong Kong Polytechnic University, Hong Kong. \\ The Hong Kong Polytechnic University, Hung Hom, Kowloon, Hong Kong (veronika.schoeb@polyu.edu.hk).}

\section{Manuscript received on 14 April 2016.}

Accepted on 14 November 2016.

83. Wei Xiaolin, Haitao Li, Nan Yang, Samuel Wong, Onikepe Owolabi, Jianguang Xu, Leiyu Shi, Jinling Tang, Donald Li, and Siad M. Griffith, "Comparing Quality of Public Primary Care between Hong Kong and Shanghai Using Validated Patient Assessment Tools," PLoS one, Vol. 10, No. 3, 2015, pp. $1-15$.

84. Ibid

85. Ibid.

86. Mike Bury, Health and Illness, op. cit:; Eduardo B. Cruz, Ann Moore, and Vinette Cross, "Clinical Reasoning and Patient-centred Care in Musculoskeletal Physiotherapy in Portugal: A Qualitative Study," Manual Therapy,Vol. 17, No. 3, 2012, pp. 246-250; Amy Hiller, Marilys Guillemin, and Clare Delany, "Exploring Healthcare Communication Models in Private Physiotherapy Practice," Patient Education \& Counseling, Vol. 98, No. 10, 2015, pp. 1222-1228. 